\title{
El testimonio de acuerdos y el testimonio de autos. ¿Un mero problema de terminología documental?
}

\author{
José Miguel LóPez VILLALBA*
}

\begin{abstract}
RESUMEN
En fechas no muy lejanas, el complejo mundo de la Diplomática se ha visto complementado con la incorporación de nuevos estudios referentes a la producción documental proveniente del campo municipal.

Entre la diversidad tipológica aportada por los concejos se encuentran unos documentos que, por la dificultad que presentan sus características internas, pudieran llevar a confusión con otras tipologías municipales. Los citados documentos, que se han venido en denominar Testimonios, recogen las actuaciones del concejo o sus representantes sobre un mismo asunto $y$ en un mismo soporte. Es decir, que teniendo un objetivo similar al del expediente administrativo, 10 resuelve de diferente manera. En este trabajo no sólo se ha aportado la denominación terminológica, sino que además se ha planteando una división

\section{ABSTRACT}

The complex world of diplomacy has recently been complemented with new studies coming from documents issued by the local councils.

Among the miscellaneous typology supplied by the councils, there are some documents that, due to their internal characteristics, can be confused with other municipal typologies.

These documents, also known as Testimonies, reflect the performance of the council or its members about a certain subject on a certain basis. This means that, having a similar purpose of a proceeding, it is managed in a different way. This report has not only supplied the terminological naming but their classification according the participants and a methodology of analysis to
\end{abstract}

* UNED. 
de los mismos según los actuantes y una metodología de análisis para el acercamiento a los citados

Testimonios, en aras de acabar con la susodicha indefinición. understand these Testimonies in order to clarify its definition.

En el mundo de la diplomática municipal debería abrirse una polémica relativa a la denominación de una serie de documentos concejiles compiejos, que, por sus características internas, bien pudieran confundirse con algunas tipologías claramente definidas. Nos estamos refiriendo a los documentos que en este análisis se han denominado "testimonios", y que, siguiendo la propuesta desarrollada más adelante, reunirán a todos aquellos documentos que recogen diversas actuaciones sobre un mismo asunto ${ }^{4}$. Pensamos que existe la necesidad de encontrar una denominación tipológica precisa para acabar con la indefinición.

El doctor López Gutiérrez, en unas sinceras líneas, nos habla de los obstáculos encontrados para la clasificación de esta tipología documental: «Es acaso el documento que a primera vista nos ha ofrecido una de las mayores dificultades a la hora de su clasificación. Dificultades porque en él y formando una unidad se incluyen, como después diremos, otros dos documentos que no son concejiles y al no ser documentos sueltos no constituyen un expediente" ${ }^{2}$.

Este escollo documental nos planteó desde el primer momento profundas dudas sobre cómo denominar a estas unidades complejas, puesto que su objetivo era claro y semejante al que tiene el expediente administrativo, ya que documenta todas las actuaciones llevadas a cabo - de iniciación, de trámite y de resolución - relacionadas con un asunto concreto. Ahora bien, mientras que el expediente incorpora cada uno de los documentos a que han dado origen estas actuaciones (instancias, informes, resoluciones), los documentos que ahora tratamos dan constancia de estas actuaciones de forma indirecta, mediante certificación, entendida en sentido amplio, como si el objetivo de tales documentos fuese dar fe de los hechos reflejados en los mismos.

\footnotetext{
1 Esta propuesta terminológica ya fue avanzada en nuestra tesis doctoral: J.M. LópEZ VILLALBA: Diplomática Municipal Medieval de Guadalajara. UNED, Madrid, 1995, págs. 380-396. Inédita.

2 A.J. López Gutiérrez, Documentación del Señorio de Cogolludo en el Archivo Ducal de Medinaceli de Sevilla (1176-1530). Zaragoza, 1989. pág. 127.
} 
Por tanto y siguiendo en este punto a la profesora Pardo Rodríguez, que utiliza el término "testimonios" para documentos de similares características, aunque en su caso para documentación notarial ${ }^{3}$, hemos optado por esta denominación.

No obstante, a pesar de que este importante conjunto documental presenta en esencia esta característica unificadora de la que venimos hablando, consideramos que pueden quedar establecidos dos tipos bien definidos a los que hemos denominado: testimonios de acuerdos y testimonios de autos.

Testimonios de acuerdos: Es el documento complejo que recoge todas las actuaciones del concejo sobre un mismo asunto.

Testimonios de autos: Es el documento complejo que recoge todas las actuaciones del alcalde como oficial judicial sobre un mismo asunto.

\section{TESTIMONIOS DE ACUERDOS}

Los testimonios de acuerdos que hemos estudiado son presentaciones de cartas ante el concejo y el reflejo de las consiguientes actuaciones y diligencias que hacen al asunto, entre las que se pueden destacar juramentos, pregones, validaciones testificales y suscripciones ${ }^{4}$.

La intención de este tipo de documentos queda claramente marcada en alguna ocasión por un brevete en el puede leerse «cabeça e pie» ${ }^{5}$, es decir, desde el principio hasta el final de todo lo relacionado con la cuestión, desde la presentación hasta la resolución del caso.

De modo que, desde el punto de vista del contenido, este tipo documental, al igual que el expediente, se caracteriza por tratar de un asunto determinado que normalmente comienza por una petición verbal o escrita de alguien, es decir, una orden de oficio. En ésto son idénticos a los testimonios de autos.

En cuanto a la forma toman la de acta en su estructura básica, iniciándose por la data. En este punto puede haber una confusión con las actas

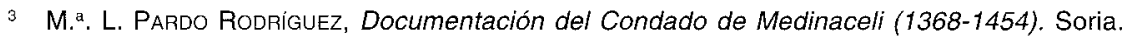
Excma. Diputación. Colección Temas Sorianos, n. ${ }^{\circ} 24 ; 1993$. págs. 112 y ss.

4 Entre los documentos estudiados en el Archivo Municipal de Guadalajara se han seleccionado un total de cinco que ordenados cronológicamente corresponden a las signaturas: $2 \mathrm{H} 0092$ 1454, $2 \mathrm{H} 0092$ 1460, 1H 0074a 001, 1H 0074a 002 y $1 \mathrm{H} 0034$.

5 AMGU 1H 0074a 002.
} 
de sesiones del concejo, pero si tenemos en cuenta que la tipología documental es la suma de las tipologías formal y jurídica, y que ambas deben tenerse en cuenta para definir un tipo concreto, pronto se deshará el equívoco. Efectivamente, desde el punto de vista formal serían actas tanto las de sesiones del concejo como los documentos que estudiamos, pero, a diferencia de estos últimos que documentan un solo negocio, las actas de sesiones recogen todos los actos tratados en el transcurso de una sesión, es decir, presentan la totalidad de acuerdos de cada una de las reuniones que, lógicamente, son diferentes entre sí, y que finalmente se recogerán en un libro que es el conjunto de todas las sesiones realizadas en un tiempo concreto. Así pues, se puede afirmar que el tema de las actas de sesiones es la propia sesión con toda la variedad de asuntos tratados durante la misma y las posteriores disposiciones sobre ellos. Por el contrario, el tema de los documentos que ahora tratamos son decisiones concretas sobre un mismo asunto. Por tanto el testimonio presenta unidad temática y las actas diversidad. Otra diferencia notoria entre ambos documentos es que las actas llevan la suscripción de los intitulantes mientras que el testimonio presenta únicamente la del escribano.

Lo que se ha visto al diferenciar entre acta de sesiones y testimonio de acuerdos es la utilización de una misma forma básica diplomática con intenciones documentales diversas. Las actas de sesiones se registran en un solo libro con la finalidad de dejar constancia de la actuación del Concejo. En cambio los testimonios de acuerdos se forman con la intención de relatar todo lo ocurrido en relación con un asunto concreto, para ello lo importante es el objeto del acto de documentación.

En realidad estas diferencias entre dos formalidades diferentes de documentar es intemporal, pensemos por ejemplo en la desigualdad entre los actuales libros de resolución de alcaldía y los expedientes.

Resumiendo, las razones por las cuales se reunen unos documentos determinados o sus certificaciones pueden ser esencialmente dos:

A) La reunión de documentos o certificación de los mismos que tienen en común tratar de un mismo asunto, da origen a dos formas básicas: el expediente y el testimonio de acuerdos.

B) La reunión de documentos o de certificaciones que tienen en común haber sido emitidos por el mismo autor u órgano, da origen a otras dos formas básicas: los libros registros de actas de sesiones y los libros de resoluciones de alcaldía.

Si hemos hecho más hincapié en la forma de los testimonios de acuerdos ha sido por plantear la similitud y la diferencia con las actas de sesiones 
del concejo, para que llegado el momento de realizar su estructura diplomática no puedan ser confundidos.

Pues bien, los testimonios de acuerdos son documentos que presentan gran complejidad en cuanto a la estructura diplomática, pero en los que puede hacerse un intento de distribución marco de las cláusulas diplomáticas.

Lógicamente y dado que van a narrar los acuerdos referentes a un asunto, comienzan, como ya se dijo, redactados en forma de acta con un protocolo inicial que detalla, en primer lugar, la data tópica y crónica, haciendo constar primeramente el nombre del lugar y a continuación, literal o numéricamente, el día del mes, el mes y el año al estilo de la Natividad, aunque en algunas ocasiones no se hace constar este último detalle.

"En la noble çibdad de Guadalajara, honçe días del mes de novienbre del año del nasçimiento de Nuestro Salvador Ihesu Christo de mill e quatroçientos e sesenta e nueve años" ${ }^{6}$.

«En el conçejo público de la çibdad de Guadalajara, sábado XXVIl días de mayo de LXIX años»?

La data deja paso generalmente al hecho de la reunión que lleva implícito la intitulación general o institucional, representada por la persona jurídica «el conçejo» y las autoridades que lo componen:

«Estando presentes el conçejo a alcalldes, alguazil, regidores, cavalleros e escuderos e omes buenos de la dicha çibdad" 8 .

Se aclara que han sido reunidos según la costumbre para resolver cuestiones que afectan a la comunidad.

«seyendo liamados a canpana repicada e monydos por su monydor, segund que lo han de uso e de costunbre» ${ }^{9}$.

A continuación se desarrolla la cita personal de todos los intitulantes según el orden jerárquico de los miembros del concejo:

«Estando presentes los nobles e muy magníficos señores don Diego Furtado de Mendoça, marqués de Santillana, conde del Real, e don Yñigo López de Mendoça, conde de Coruña, e los señores don Furtado de

AMGU 1H 0074a 002.

AMGU 1H 0074a 001.

AMGU $1 \mathrm{H} 0034$.

AMGU $1 \mathrm{H} 0034$. 


\begin{abstract}
Mendoça e don Yñigo de Mendoça e don Pedro de Mendoça, su hermano, e los honrrados, Ferrando Gutiérrez Suárez de Medina e Juan Núñez de Toledo e Pedro de Camargo, alcalldes, e Alonso de la Serna, alguazil, e Sancho Fernández de Castro e Rodrigo de la Torre e Diego de Garavito e Gonçalo de León e Alfonso Páez de Eçija e Luys Gómez de Córdova, regidores; e Ferrando Rodrigo de Sant Viçente, alcallde de los padrones, e el liçençiado Lope Gonçález de Cañizares e Juan Lorenço e Juan Beltrán de Caraçuelo e Ruy Díaz de Hita e Pedro de Alva e Gonçalo de Quando e Manuel de Toro e Sancho de Frías e Lope de Pastrana e Alfonso de Alcaraz, el de Cuenca, e maestro Juan de Bruxelas e Pedro de Medina e Juan de Córdova e Alfonso Gonçález de Sahagund e el bachiller Pedro Ruyz de Valfermoso e Diego Gonçález de Guadalajara e Lope Muñíz, sastre, e Fernando de Guadalajara, criado del señor don Juan de Mendoça» ${ }^{10}$.
\end{abstract}

De la presencia del escribano y los testigos queda certeza escrita por medio del desarrollo del nombre y apellidos del primero, así como de su cargo y lugar de ejercicio, mientras que de los segundos se da referencia por medio de la expresión «de yuso escriptos», y posteriormente aparecen identificados en las validaciones.

Ante el escribano aparece el interesado presentando su petición, que puede ser desde una carta del rey nombrándole regidor hasta una carta de repartimiento.

«el dicho Ferrando Sánchez de Carrión, presentó e leer fizo por mí el dicho escribano una carta del rey nuestro señor, escripta en papel e firmada de su nonbre e sellada con su sello de çera colorada..." ${ }^{11}$.

Se trata, como ya anunciamos, de comunicaciones externas al Concejo que deben ser presentadas ante éste para que se lleven a cabo las diligencias oportunas. Estos documentos insertos harían de expositivo si no fuese porque con posterioridad siguen apareciendo sucesivos testimonios con sus respectivas validaciones, ya que, en realidad, no estamos ante una unidad archivística simple sino compleja que ofrece una serie de hechos certificados por el rogatario y validados testificalmente sobre un mismo asunto.

Tras asegurarse de la validez de la carta se anuncia la copia del documento «verbo ad verbum»:

"su tenor de las cuales uno en pos de otro es éste que se sigue» ${ }^{12}$.

\footnotetext{
Ibidem.

AMGU 1 H0074a 002.

AMGU $1 \mathrm{H} 0034$.
} 
O se permuta su redacción literal por una fórmula de sustitución:

«aquí ha de entrar la carta del pedido» ${ }^{13}$.

El peticionario solicita a continuación de la lectura de la carta que ésta se acate por medio de juramento y después se pregone. De todos estos hechos acontecidos en el Concejo se va dejando constancia a modo de expositivo hasta llegar a la disposición que, por medio de verbos iusivos, ordena generalmente pregonarla y dar traslado de la misma a los destinatarios finales:

«E en cunpliéndola dixieron que la mandavan pregonar públicamente por la dicha çibdad e asy mesmo que mandavan e mandaron dar traslado de ella al común e omes buenos pecheros de la dicha çibdad e su tierra e de las otras villas e lugares de su arçedianadgo que lo querrán para que por virtud de ella repartan e cojan el pedido en ella contenido e fagan e cunplan todo lo otro en la dicha carta contenido, segund que por ella el dicho señor rey lo envía mandar» ${ }^{14}$.

A continuación, el presentador de la carta pide al escribano que le dé testimonio de todo lo sucedido hasta el momento, y los testigos validan la verdad de lo reflejado.

El mismo día es pregonada la carta y nuevamente se pide por parte de su portador testimonio del hecho, esta vez signado, y por último hay una nueva validación de los testigos junto con el reconocimiento explícito del escribano aclarando que todo ocurrió en la misma fecha.

Como resumen de los expuesto hasta aquí se ha considerado conveniente exponer un breve esquema que precise la sucesión de las actuaciones reflejadas:

- Data, intitulación y constancia de ayuntamiento.

- Presencia del escribano y testigos.

- Presentación de la carta y traslado de la misma.

- Las cláusulas de petición de acatamiento.

- El acto de acatamiento de la misma con todas las fórmulas de juramento.

- La petición de testimonio escrito por el presentador de la carta.

- La validación de todo lo anterior.

13 AMGU 1H 0074a 002.

${ }^{14}$ Ibidem. 
- El pregón de lo contenido en la carta.

- La validación del escribano y la validación testifical.

Pero los hechos reflejados no siempre ocurren en un solo día, es más, generalmente la mayor parte de los testimonios responden a una temporalidad más dilatada, llegando incluso a contabilizarse por años. El documento $1 \mathrm{H} 0034$ se enmarca bien en este grupo en que las actuaciones relatadas tendrían un arco temporal más amplio, pues comienzan el día 4 de julio de 1470 y finalizan tres meses más tarde. Lógicamente, cuando el proceso documental reflejado se extiende la complejidad documental va aumentando en proporción a la cantidad de tiempo, ya que se van añadiendo más y más documentos. No obstante, la estructura diplomática del conjunto será similar a la presentada en el documento anterior, aunque con multiplicación de expositivos, tantos como cartas o relatos se vayan añadiendo, pero con un solo dispositivo final de aceptación de lo presentado:

«que mandavan e mandaron recudir al dicho Ferrando Pérez, regidor, con la quitaçión e salario e otros derechos al dicho oficio de regimiento anexos e pertenesçientes, segund que mejor e más conplidamente recuda e cada uno de los otros regidores de la dicha çibdad segund e en la manera que el dicho señor rey lo enbía mandar por la dicha su cartas ${ }^{15}$.

A modo de conclusión insistimos en la complejidad de lo presentado, pues, como se ha visto, de cada acto o hecho del negocio se va pidiendo el correspondiente testimonio del escribano y la validación testifical, de modo que se insertarán cronológicamente unos detrás de otros todos los hechos referentes a esta cuestión, como si de un precedente de los actuales expedientes se tratase.

\section{TESTIMONIOS DE AUTOS}

Este tipo de testimonios son los que recogen las actuaciones ante un alcalde como oficial judicial de! Concejo. Ahora bien conviene precisar que estamos hablando de autos, pero no como decreto y determinación dada o pronunciada jurídicamente por el alcalde sobre alguna causa civil o criminal en su condición de oficial de justicia, sino como acto o hecho acaecidos y que éste testimonia, es decir, lo que podríamos alcanzar a definir, llegando más lejos, como testimonio de actuaciones.

15 AMGU $1 \mathrm{H} 0034$. 
Ejemplificaremos seguidamente la tipología de este grupo a través de uno de los documentos catalogados como tales en el Archivo Municipal de Guadalajara ${ }^{16}$.

El negocio jurídico que contiene el documento $1 \mathrm{H}$ 0071a es el auto de recibimiento de carta de privilegio del rey a favor del manasterio de San Bartolomé de Lupiana, con su posterior obedecimiento y pregón. Como vemos, el contenido es similar a lo ya visto en los testimonios de acuerdos, con la diferencia de que la actuación en aquellos era ante el concejo pleno y en éstos será ante el alcalde.

Ya se expuso al hablar de los testimonios de acuerdos, la dificultad que presentaba proponer una distribución clausular diplomática, debido a la cantidad y variedad de actuaciones testimoniales. De cualquier forma en un intento de realizar una propuesta similar referida a este documento tipo que ahora nos ocupa podríamos decir que está encabezado por una datación completa seguida de la intitulación del alcalde y procurador:

«ante Alvar Rodríguez de Hita, alcallde en la villa de Guadalajara»

Sigue la inserción del documento real haciendo la funciones de expositivo y finalizando con el acatamiento por parte del alcalde. El dispositivo previa "petitio", recoge la orden del alcalde de pregonar en varios lugares el documento real anteriormente citado, acompañada de sus correspondientes apariciones testificales, cerrándose el documento con la validación de los testigos y el escribano.

En conclusión, ambos tipos de testimonios, de acuerdos y de autos, presentan un desarrollo interno similar, lo cual nos lleva a afirmar que se trata de una misma tipología básica diferenciada por los intitulantes. En el primer caso, el concejo reunido en ayuntamiento, y en el segundo, el alcalde, que actúa como oficial de justicia del concejo. En ambos con la inestimable ayuda del escribano que, ejerce asimismo como oficial del concejo y por orden de los respectivos intitulantes, o a petición de los que se presentan con una determinada cuestión, dará testimonio de todo lo tratado sobre la misma, insertando en su relato unos hechos a continuación de otros.

De esta forma surge un rico conjunto informativo reflejado en una exclusiva unidad documental que, si bien archivísticamente pudiera resultar compleja por su similitud con un expediente administrativo, presenta todo su contenido perfectamente distribuido con arreglo a una estructura diplomática, originando en consecuencia un tipo documental específico merecedor de una terminología propia.

16 AMGU 1H 0071a, 1H 0074a 003 y $1 \mathrm{H} 0059$. 